\title{
CIÊNCIA, INTELIGÊNCIA ARTIFICIAL E PÓS-MODERNIDADE
}

\section{Ciencia, Inteligencia Artificial y Pos-Modernidad}

Ziléa Baptista Nespoli ${ }^{1}$

\section{Resumo}

A "crise da ciência", ocorrida nos últimos decênios do século XIX, coloca-nos para refletir sobre o que hoje consideramos como: conhecimento, saber, ciência e "saberes", pois, nem todo o saber é científico e a ciência precisa de todos os "saberes" para se legitimar. Essa discussão perpassa pela pedagogia crítica e todo um discurso atual, em que a idéia de informatização está ligada ao armazenamento dos "saberes", no computador. Surge com a era PósModerna a sociedade do conhecimento onde a "pessoa instruída" deverá estar preparada para viver num mundo global. Será, pois, "uma cidadã do mundo", em que o conhecimento será o capital do futuro. Para tal será preciso desenvolver estudos de técnicas que tornem os computadores capazes de decisões, de forma parecida com o ser humano. Essas técnicas fazem parte da inteligência artificial (IA), um ramo da ciência da computação. Com a nova visão de mundo, a educação é chamada a avançar com criatividade na perspectiva tecnológica para que, nesse mundo plural, possamos, ao transformar a cultura informática em um instrumento de solidariedade social, contribuir para a formação de cidadãos e atores sociais.

Palavras-chave: Computador; Sociedade do conhecimento; Inteligência artificial (IA); Solidariedade social; Saberes.

1 Pedagoga pela UFF; Mestre em Educação pela UFF; Doutora em Educação a Distância - AWU - IWOA, Professora titular da Universidade Castelo Branco; Coordenadora Pedagógica da CEAD/UCB.

Endereço para correspondência: Rua 23 Q 66 lote 9 - Maravista - Itaipu, Niterói, RJ - CEP: 24342-330

e-mail - nespoli@ar.microlink.com.br 


\section{Resumen}

La "crisis de la ciencia" acontecida en los últimos decenios del siglo XIX nos desafía a reflexionar sobre los conceptos actuales de conocimiento, saber, ciencia y "saberes", pues no todo saber es científico y la ciencia se legitima apoyaridose en todos los "saberes". Esa discusión se hace presente en la pedagogía crítica y en un discurso actuales, el cual la idea de informatización está unida al almacenamiento de los "saberes" en el ordenador. Con la era PosModema hace su aparición la sociedad del conocimiento que obliga a las "personas instruidas" a prepararse para vivir en un mundo global. Serón pues ciudadanos del mundo en que el conocimiento será el mayor valor. Para eso será necesario desarrollar estudios de técnicas que hagan que los ordenadores, semejantemente a los seres humanos, sean capaces de tomar decisiones. Estas técnicas hacen parte de la inteligencia artificial (IA), un ramo de la ciencia de la computación. Esa nueva visión del mundo desafía a la educación a avanzar con creatividad en la perspectiva tecnológica para que, en este mundo global, se pueda aprovecharla cultura informática como instrumento de solidariedad social, contribuyendo a la formación de ciudadanos e actores sociales.

Palabras-clave: Computadora; Sociedad del conocimiento; Inteligencia artificial (IA); Solidariedad social; Saberes.

\section{A sociedade do conhecimento}

Assistimos a modificações substantivas nos estudos da ciência e da universidade, por volta dos anos 50, com o início da chamada "era pósindustrial". O mais importante nesse processo de modificação, cuja origem encontra-se na "crise da ciência" (e da verdade) ocorrida nos últimos decênios do século XIX, não foi apenas a eventual substituição de uma "má" concepção da ciência (a empirista, por exemplo) por outra qualquer. O que de fato vem desde então ocorrendo é uma modificação na natureza mesma da ciência (e da universidade) provocada pelo impacto das transformações tecnológicas sobre o saber. A conseqüência mais imediata desse novo momento foi tornar ineficaz o quadro teórico proporcionado pela metafísica moderna que elegeu como sua questão a problemática conhecimento, secundarizando as questões ontológicas. Assim, fez da filosofia um metadiscurso de legitimação da própria ciência. A modernidade do quadro teórico apresentado está exatamente no fato de conter certos récits aos quais a ciência moderna teve de recorrer para legitimar-se como saber: dialética do espírito, emancipação do sujeito razoável ou do trabalhador, crescimento de riqueza e outros. Desde o momento em que se invalidou o enquadramento metafísico da ciência moderna, vem ocorrendo não apenas a crise de conceitos caros ao pensamento moderno, tais como "razão", 
"sujeito", "verdade", "progresso". Constatamos que ao lado dessa crise opera-se, sobretudo, a busca de novos enquadramentos teóricos ("aumento da potência", "eficácia", "otimização das performances do sistema") legitimadores da produção científico-tecnológico numa era que se quer pós-industrial.

Diante dessa realidade o artigo tem como objetivo estudar a sociedade do conhecimento e ressaltar que, nessa sociedade, os indivíduos são fundamentais. $\mathrm{O}$ conhecimento não é impessoal como o dinheiro. $\mathrm{O}$ conhecimento não reside em um livro, em um banco de dados, em um programa de software; estes contêm apenas informações. O conhecimento está sempre incorporado a uma pessoa, é criado, ampliado ou aperfeiçoado por uma pessoa, é aplicado, ensinado e transmitido por uma pessoa. Portanto, a passagem para a sociedade do conhecimento coloca a pessoa no centro. Ao fazê-lo, ela levanta novos desafios, novas questões e novas perguntas sem precedentes, a respeito do representante da sociedade do conhecimento, a pessoa instruída.

Em todas as sociedades anteriores, a pessoa instruída era um ornamento. Na sociedade do conhecimento, a pessoa instruída é o "arquétipo" social. Ela define a capacidade de desempenho da sociedade, mas também incorpora seus valores, crenças e compromissos. Essa pessoa instruída irá representar a sociedade na sociedade, Pós-Moderna, na qual o conhecimento tornou-se o recurso principal.

A sociedade do conhecimento precisa ter em seu âmago o conceito de pessoa instruída. Este terá que ser um conceito universal, precisamente porque a sociedade do conhecimento é uma sociedade de conhecimentos e é global - em seu dinheiro, sua economia, suas carreiras, sua tecnologia, suas questões básicas e, acima de tudo, em suas informações. Ela requer um grupo de liderança que possa focalizar tradições locais, particulares e separadas sobre um compromisso comum de excelência e sobre respeito mútuo.

A sociedade do conhecimento necessita exatamente do oposto daquilo que propõe os desconstrucionistas, as feministas radicais ou os antiocidentais. Ela precisa exatamente daquilo que eles rejeitam: uma pessoa universalmente instruída que concentre seu conhecimento no presente e na moldagem do futuro, valendo-se da grande herança do passado.

A pessoa instruída de amanhã terá que estar preparada para viver em um mundo global, que será "ocidentalizado", mas também, e cada vez mais, um mundo tribalizado. Ela deverá se tornar uma "cidadã do mundo" - em visão, horizonte e informação. Ela deverá recorrer a outras culturas e, no processo, enriquecerá a sua própria cultura local.

Assim como a Revolução Industrial não acabou com a agricultura, a Revolução da Informação não acabará com a indústria. Ninguém pode 
dizer com certeza que novas formas de trabalho e prosperidade essa revolução criará; em uma revolução, a única certeza é surpresa. Mas já é óbvio que o sucesso em uma economia baseada no conhecimento depende de novas habilidades e novos tipos de organizações e gerenciamentos.

A nova era já chegou, mas suas transformações sociais e econômicas ainda não chegaram ao auge.

\section{Pedagogia crítica, ciência e pós-modernidade}

Ao falarmos da pedagogia crítica e da Pós-Modernidade, não podemos deixar de mencionar alguns educadores, mundialmente reconhecidos por terem contribuído grandemente para o desenvolvimento dessa linha de pensamento, não somente pelo refinamento teórico, mas por causa do sucesso de suas práticas pedagógicas. Assim, podemos destacar: Paulo Freire, Michael Apple e Henry Giroux.

Freire acreditava que a pobreza e o analfabetismo estão diretamente relacionados com estruturas sociais opressivas e com o exercício desigual de poder na sociedade.

Seu trabalho é primariamente dirigido a ajudar estudantes a tornarem-se criticamente instruídos, em oposição a funcionalmente instruídos ou culturalmente instruídos. Ele define cultura como um campo de batalha a respeito da significação, um diálogo de muitos lados que nunca é neutro. Para Freire, linguagem e cultura refletem sempre uma pluralidade de valores, vozes e intenções que geram o diálogo. Uma perspectiva como essa chama atenção para a intensidade das contradições sociais dentro de sistemas lingüísticos e simbólicos. A cultura nunca é despolitizada; ela permanece sempre amarrada aos relacionamentos sociais e de classe que a informam.

Os seres humanos não flutuam sem objetivo em um mar de abstrações; eles estão firmemente enraizados na batalha histórica e nunca perdem sua capacidade de sofrer ou sua vontade de mudar o mundo. (FREIRE, apud MACLAREN, 1997, p. 328)

O trabalho de Freire começa e termina com o tema individual. Seu trabalho é ligado ao capital cultural do oprimido; ele usa o seu próprio vocabulário; idéias e valores no encontro letivo. Suas teorias crescem de uma "cultura do silêncio", em que pessoas são vitimadas e submersas em "semi-intransitividade"; eles se tornam reconhecidos como um projeto revolucionário... engajadas em uma luta contra estruturas opressivas e desumanas. 
Seu projeto utópico salienta a necessidade de uma crença fundamental no diálogo humano e comunidade. A dimensão utópica e natural a qualquer projeto revolucionário dedicado à transformação e recriação do mundo, dizia Freire.

O trabalho de Apple representa um avanço formidável na conceituação da relação entre as escolas, a arena da cultura e a economia. No centro da análise da escolaridade e da grande sociedade de Apple estão as relações de classe, gênero, raça e formas culturais de resistência. As escolas, argumenta ele, são aparatos produtivos e reprodutivos do Estado. Podemos conceituar a cultura escolar não somente como um produto (conhecimento técnico e administrativo necessário para manter capital e poder circulando nas mãos da ordem dominante), mas também como uma esfera relativamente autônoma de "experiências vividas" e "padrões diários de interação" de estudantes e professores, incluindo formas culturais relacionadas à classe e gênero.

A contribuição original de Apple para a pedagogia crítica está na sua habilidade de articular claramente como a forma curricular, a transmissão de vários conhecimentos e o ensino como um processo de trabalho estão ligados à lógica e acumulação do capital. Em sua opinião, uma reforma educacional bem-sucedida deve incluir um número de dinâmicas: lutas exteriores sobre modos de produção; reformas no local de trabalho; a democratização de procedimentos decisivos e práticas sociais nas escolas; e os esforços de professores para fazer alianças multiclássicas com movimentos sociais progressivos, na grande sociedade.

O trabalho de Henry Giroux tem afetado tanto a teoria social moderna com as principais correntes da pedagogia crítica. Acredita que as escolas não devem ser vistas apenas como locais de instrução, mas como complexos culturais dominantes e subordinados, cada uma ideologicamente ligada ao poder que possui em definir e legitimar uma construção particular da realidade. Como espaços culturais, as escolas são terrenos controversos em que diferentes valores, convenções e conhecimentos alternadamente cruzam-se, justapõem-se e excluem uns aos outros.

Giroux sugere que a análise crítica das escolas não tem dado suficiente ênfase ao potencial das escolas como locais de transformação social. Ele argumenta que as escolas são mais do que um mecanismo de dominação; são também lugares onde formas particulares de conhecimento, relações sociais e valores podem ser ensinados para educar estudantes a tornarem seu lugar na sociedade em uma posição de controle, em vez de uma posição de subordinação ideológica e econômica.

Giroux, juntamente com Michael Apple e outros, argumenta que as escolas são locais parcialmente autônomos. Dessa maneira, os estudantes po- 
dem resistir à lógica dominante às restrições incorporadas nas leis escolares e convencionais. Para Giroux, a escolaridade é uma forma de produção cultural pela qual são estabelecidos vários processos: a seleção e legitimação do conhecimento escolar e subjetividades estudantis; a organização e aprovação de formas particulares de experiência; e o desenvolvimento de formas de subjugação resultantes da execução de formas particulares de autoridade.

Ao analisarmos o pensamento dos educadores acima, verificamos que a pedagogia, em seu sentido mais crítico, ilumina a relação entre conhecimento, autoridade e poder. Ela chama a atenção para questões que dizem respeito a quem tem controle sobre as condições para a produção de conhecimento.

Assim, a pedagogia crítica, vista como uma forma de ativismo político, refere-se a um esforço deliberado, por parte de trabalhadores culturais, para influenciar a forma como as subjetividades e o conhecimento são produzidos no interior de conjuntos particulares de relações sociais.

A pedagogia crítica não reduz a prática educacional a uma questão de eficiência. Ela enfatiza, em vez disso, questões sobre "qual conhecimento é mais válido, o que devemos desejar e o que significa saber alguma coisa". (SIMON apud SILVA, 1998, p. 139).

Nesta era, o pós-moderno, enquanto condição da cultura, caracteriza-se exatamente pela incredulidade perante o metadiscurso filosóficometafísico, com suas pretensões atemporais e universalizante. O cenário pós-moderno é essencialmente cibernético-informático e informacional. Incrementam-se os estudos sobre a "Inteligência Artificial" e o esforço sistemático no sentido de conhecer e estruturar o funcionamento do cérebro bem como o mecanismo da vida. Logo predominam os esforços (científicos, tecnológicos e políticos) no sentido de informatizar a sociedade. Na pós-modernidade com sua "vocação" informática e informacional, "investe" sobre esta concepção do saber científico. O séc. XX vem sendo o palco de uma descoberta fundamental: a fonte de todas as fontes chama-se informação e que a ciência - assim como qualquer modalidade de conhecimento - nada mais é do que um certo modo de organizar, estocar e distribuir certas informações.

A era pós-moderna começa a ver a ciência como um conjunto de mensagens possível de ser traduzido em "quantidade (bits) de informação". Logo, se as máquinas informáticas justamente operam traduzindo as mensagens em bits de informação, só será "conhecimento científico" certo tipo de informação traduzível na linguagem que essas máquinas utilizam ou então compatível com ela. O que se opõe com o tratamento informático da "mensagem" científica é na verdade uma concepção operacional da ciência. 
O que vem se impondo é a concepção da ciência como tecnologia intelectual, ou seja, com valor de troca e, por isso mesmo, desvinculada do produtor (cientista) e do consumidor. Assim, as delimitações clássicas dos campos científicos entram em crise, se desordenam. O contexto da deslegitimação Pós-Moderna não pode, evidentemente, passar sem um dispositivo de legitimação. "A administração da prova”, escreve Lyotard (1986),

que em princípio não é senão uma parte da argumentação destinada a obter o consentimento dos destinatários da mensagem científica, passa assim a ser controlada por um outro jogo de linguagem onde o que está em questão não é a verdade mas o desempenho, ou seja, a melhor relação input/output (p. 83).

Parece-nos razoável dizer que o texto de Lyotard contém, implícita, uma observação que reputamos fundamental: o contexto pós-moderno tende a eliminar as diferenças epistemológicas significativas entre os procedimentos científicos e os procedimentos políticos. Francis Bacon, preocupado com o presente e com o reforço do critério de desempenho critério tecnológico - visando com o uso o reforço da "realidade" e o aumento das chances de se ter "razão", parece ter abandonado os caminhos da utopia. Observa-se, assim, o esforço do filósofo de superar o divórcio entre inteligência e emoção. Para isso é sem dúvida necessário que o conhecimento esteja mais perto do concreto, do presente, cooperando com as forças do acontecimento, descodificando e dando coerência aos detalhes da cotidianidade.

\section{Desenvolvimento tecnológico, inteligência artificial e educação}

A Inteligência Artificial (IA) é um ramo da ciência da computação que quer dotar os computadores de inteligência. Desde os primeiros computadores, a questão da inteligência ligada a estas máquinas tem sido tema de debates acalorados, muitas vezes com base mais em informações imaginárias do que em fatos objetivos.

Nos tempos em que estamos vivendo, o espírito de pesquisa mostra-se mais vivo do que em qualquer outra época da história da humanidade. Atualmente, a orientação da computação, em relação às realidades do homem moderno, dirige-se para o desenvolvimento de equipamentos (hardware) e programas (software) que busquem ajudar o homem nas tarefas mais automáticas, a fim de poder libertá-lo para tarefas mais condizentes com as características de um ser humano que são: família, humanidade, lazer, artes, coisas que um computador não pode se dedicar. 
Estamos ficando cada vez mais sensível ao mundo das idéias, das descobertas em favor da humanidade e não contra elas. Até bem pouco tempo só os mais cultos tinham essa sensibilidade, que hoje se generaliza. Surge assim a questão: "Pode um computador suplantar o homem, como vemos em filmes de ficção científica?"

A Inteligência Artificial é o produto mais importante da história do desenvolvimento da tecnologia dos computadores. Desde a invenção do circuito integrado, trata-se da última palavra na área de informática, cujos resultados de sua utilização prática já estão sendo consagrados internacionalmente. $\mathrm{O}$ conhecimento está para a Inteligência Artificial assim como a informação esteve até agora para os atuais sistemas.

Atualmente, afirma-se que o conhecimento é o capital do futuro. Se você usá-lo como recurso estratégico que ele é, seu impacto em profundidade e racionalização gerará repercussões econômicas significativas para seu empreendimento. As aplicações práticas da Inteligência Artificial para as empresas são muitas. Os produtos com IA foram desenvolvidos para ajudá-lo a racionalizar e gerenciar uma empresa, objetivando aumentar a sua produtividade, bem como colocá-lo à frente dos seus concorrentes com significativo retorno na relação custo/benefício.

Empresas especializadas em IA desenvolvem programas na área de Tecnologia do Conhecimento. São produtos e programas que colocam a sua disposição, de forma prática, toda a potencialidade da tecnologia da Inteligência Artificial, compatível com quase todos os equipamentos de processamento de dados encontrados atualmente no mercado. Essas empresas podem ajudá-lo também a constituir protótipos de Sistemas Especialistas ou apoiá-lo na implementação de outros produtos de Inteligência Artificial.

Na Inteligência Artificial estudam-se técnicas que tornam os computadores capazes de tomar decisões de forma parecida com o ser humano. Estudam-se técnicas de: representação de conhecimentos, heurísticas (soluções de problemas), raciocínios lógicos e nebulosos que darão boas, mas nem sempre, soluções ótimas e linguagens especiais, para trabalhar com conhecimentos.

Podemos citar algumas vantagens e benefícios que a tecnologia da IA traz, na prática:

- menos erros, devido ao aumento do conhecimento em níveis inferiores da organização;

- redução dos tempos de resolução de problema;

- maior produtividade dos especialistas, geralmente caros;

- maior flexibilidade para os funcionários que podem operar em diversas áreas, porque, ao invés de aprender conhecimentos especializados para realizar uma tarefa, basta que aprendam a operar um programa; 
- preservar os conhecimentos para a empresa, ainda que o funcionário venha a se desligar da empresa;

- com o conhecimento sendo formalizado, a empresa pode ver explicitamente os pontos que podem ser melhorados.

As empresas que estiverem mais atualizadas com as últimas tendências tecnológicas têm mais chances de utilizá-las em seu benefício, podendo, assim, ficar um passo à frente da concorrência, cada vez mais acirrada nos dias de hoje, e ainda agradar o consumidor, que cada vez mais está consciente de seus direitos e exigente em relação à qualidade.

No Brasil, torna-se essencial discutir e implementar, no curto prazo, uma política global de treinamento com vistas à nossa capacitação imediata para utilizar adequadamente o instrumental tecnológico disponível no mercado, de modo a que se desenvolva no país uma tecnologia de uso compatível com demandas represadas.

Sem que venhamos a vencer o desafio da educação global, básica, em todos os níveis e latitudes, a questão da formação de mão-de-obra adequadamente treinada continuará a ser apenas uma retórica inteiramente distanciada da realidade. A qualidade da educação é fator preponderante para o sucesso de qualquer empreendimento, seja no micro-mundo da empresa ou no contexto amplo de uma nação. O avanço nessa área é ingrediente fundamental para alavancar a competitividade nesta década e, disso, não temos mais como recuar, neste limiar do terceiro milênio.

A educação escolar neste final de século é chamada a avançar com criatividade nesta perspectiva, contribuindo, assim, para que o novo milênio possa favorecer um mundo plural, em que todos se sintam cidadãos e atores sociais.

Segundo Terry Winograd, em Do Caos à Inteligência Artificial (1993), "o computador é capaz de armazenar ou manipular as idéias humanas mas, de certo modo ele não tem mais idéias do que um livro". (p. 237)

Uma grande parte da pesquisa no campo da Inteligência Artificial trata do aprendizado não mais como um processo de armazenagem de informação, mas como algo que tem a ver com a sua reorganização. 0 computador começa com um dispositivo de "armazenagem de base" e, durante a coleta da informação, esse "conhecimento" é reorganizado, reestruturado de maneira mais eficaz de acordo com a necessidade. Existem, portanto, processos de aprendizagem mais elaborados, mas que ainda são entravados pela "estrutura inicial" da máquina. Aquilo que um computador pode aprender é determinado, de certo modo, pelo que ele já sabe e é difícil imaginar a criação de uma estrutura suficientemente geral e aberta para que se possa produzir um pensamento inovador.

A tecnologia não determina o seu uso: nenhuma técnica pode ser 
utilizada aleatoriamente e todo aparelho só permite uma certa gama de aplicações. Por exemplo, os computadores podem ser bem eficazes para promover a comunicação em uma sociedade descentralizada: se escrevo um romance e desejo difundi-lo, devo antes publicá-lo, o que significa ter a aprovação de uma pessoa influente no mundo da edição. Se existe uma rede de comunicação informatizada, poderia colocar o meu romance à disposição dos interessados sem qualquer autorização prévia. Nesse sentido, a informatização ajudará na descentralização, assim como na redução do controle. Mas, simultaneamente, os computadores podem ser utilizados também por um sensor do governo, a fim de examinar todas as informações difundidas e impedir, assim, a livre-expressão por meio escrito. 0 mesmo dispositivo, o mesmo computador, poderia, portanto, ser utilizado com finalidades bem diferentes, até mesmo contraditórias.

Na questão educacional destacamos Seymour Papert, o inventor de uma linguagem de programação clara e estruturada (Logo), que permite às crianças, mesmo as bem jovens, mover um cursor chamado "tartaruga" em uma tela, formando figuras geométricas bastante elaboradas, que se propôs a colocar a inteligência artificial a serviço da pedagogia e, de uma maneira geral, de transformar a cultura informática em um instrumento de solidariedade social.

A tartaruga Logo é para Papert o que a maçã foi para Newton: 0 símbolo de uma ciência dedicada ao senso comum. Graças a ela, a inteligência artificial promete elucidar os processos pelos quais aprendemos e poderemos aprender ainda mais.

Seu projeto é inteiramente voltado contra a sujeição do homem pela máquina. Em, Do Caos à Inteligência Artificial (1993), Papert ressalta: "Nas escolas Logo, contata-se muito mais interações entre as crianças do que nas escolas clássicas. Penso, aliás, que a coisa mais excitante feita por Logo foi atrair os professores humanistas para a informática”. (p. 246)

Não é o computador em si que isola os homens, mas a cultura ambiente na qual ele "reina" ... A questão primordial para o futuro do homem é saber se a "cultura informática" evoluirá no sentido orwelliano do isolamento ou, pelo contrário, como um instrumento de solidariedade cultural e de inserção social. Trata-se da escolha de um modo de vida. Nada na própria tecnologia indica a direção que ela irá tomar. Papert enfatiza: "Espero que o computador jamais seja capaz de "pensar" como nós, porque temos vontade política e social de impedir isso". (PESSIS-PASTERNAK, 1993, p. 246).

Os utopistas querem que o computador possa encontrar soluções para todos os nossos problemas, enquanto os céticos nos advertem para os perigos dessa máquina. Papert pensa que ambos estão errados: "Esse futu- 
ro informático ainda está por se fazer; é portanto um ato de escolha que seja um futuro orwelliano ou um futuro humano". (in: PESSIS-PASTERNAK, 1993, p. 253)

\section{A nova visão de mundo}

Pierre Levy, no livro Do Caos à Inteligência Artificial (1993), faz uma análise partindo de ampla pesquisa sobre as novas técnicas de criação científica e artística e traça as linhas-mestras de nossa nova cultura. Prova que as simulações numéricas e a transformação em algoritmos dos raciocínios científicos nos levam a considerar os objetos físicos, e até mesmo os seres humanos, como simples sistemas de tratamento da informação, suprimindo dessa maneira a parte essencial do real que jamais será redutível ao cálculo.

A informática afeta hoje a maioria de nossas atividades socioculturais, a saber a ciência, a arte ou o poder político. "O novo paradigma que vai modificar profundamente a nossa visão de mundo, é o da "informação operacional" que se baseia no cálculo e na análise". (LEVY; p. 256).

A informática hoje é uma tecnologia de gestão de técnicas. Ela é antes de mais nada um novo modo de reflexão, de informação, graças ao qual a nossa visão de mundo é radicalmente transformada.

$\mathrm{O}$ mundo de acesso à cultura se dá agora pelo telefone celular, e as crianças aprendem graças ao computador. A informática se tornou uma nova "pele", gerindo as nossas relações com o nosso meio. "Não creio que criadores de grandes sistemas de informática busquem o "poder". Eles exercem sua atividade criadora, quase lúdica, de concepção de sistemas inéditos, com paixão" (LEVY; p. 259).

Com certeza, somos todos, de certa maneira, "prisioneiros" desses sistemas de comunicação concebidos por uma carência que ninguém poderia prever que redefiniria de modo tão radical a nossa relação com 0 mundo.

\section{Referências}

APPLE, M.W. Educação e poder. Porto Alegre:Artes Médicas,1989.

CONNOR, S. Cultura pós-moderna: introdução às teorias do contemporâneo.

São Paulo,SP: Loyola, 1995. 
GIROUX, H.A.S chooling and the struggle for public life. Mineápolis:University of Minnesota Press.

HALL, S. A identidade cultural na pós-modernidade. Rio de Janeiro,RJ: DP§A, 1998

LYOTARD, Jean-François. O pós-moderno. Rio de Janeiro,RJ: José Olímpio, 1986.

MACLAREN, P. A vida nas escolas: uma introdução a pedagogia crítica nos fundamentos da educação. 2. ed. Porto Alegre: Artes Médicas, 1997.

PESSIS-PASTERNAK, G. Do caosà inteligência artificial: quando os cientistas se interrogam. São Paulo,SP: Editora da UEP, 1993.

SILVA, T. T. da (org.). Alienígenas na sala de aula. 2. ed. Petrópolis: Vozes, 1998.

Recebido em: 04 de março Aprovado em: 05 de maio 